\title{
Comparative Study of Three Different Brands of Glimperide
}

\author{
Syeda Arshi Zafar ${ }^{1}$, Safila Naveed ${ }^{1 *}$, Rafia Usman Khan ${ }^{2}$ and Halima Sadia ${ }^{1}$ \\ ${ }^{1}$ Faculty of Pharmacy, Jinnah University for Women, Karachi, Pakistan \\ ${ }^{2}$ Department of Chemistry, NED University of Engineering and Technology, Karachi, Pakistan
}

\begin{abstract}
Glimepiride is an antidiabetic agent used for lowering blood glucose levels. It induces the activity of peroxisome proliferator-activated receptor-gamma (PPAR gamma). It lowers blood glucose levels by binding to ATP-sensitive potassium channel receptors on the surface of pancreatic cells. The purpose of this study was to perform a comparative analysis of different physicochemical parameters (weight variation, hardness, thickness, friability, disintegration time, and dissolution time) of 3 different commercially available brands of glimepiride in the market. Statistical analysis revealed minor variations in the results. It was found that GETRYL showed the highest $\%$ dissolution among all the 3 brands whereas AMARYL took the least time to disintegrate. According to the results of the friability test, DIABOLD showed the highest stability in the friabilator. However, all 3 brands complied with the official pharmacopoeial limits. The quality of the drug largely influences its therapeutic activity. Hence, owing to the similar physicochemical profile, all the 3 brands can be interchangeably used.
\end{abstract}

Keywords: Glimepiride, weight variation, dissolution, disintegration.

\section{INTRODUCTION}

Excessive levels of sugar in the blood leads to a disease called Diabetes Mellitus [1]. In a disease-free state, energy to the body is provided by utilizing glucose which is generally achieved from food intake [2]. The utilization of glucose is mediated by the hormone "insulin" produced by the beta cells of the pancreas. Insulin is released in response to the elevated levels of glucose in the body. If the body is unable to secrete insulin or insulin is not properly utilizing glucose to produce energy, the glucose starts to accumulate in the blood and eventually manifests as Diabetes Mellitus. Drugs that mimic the secretion or improve the uptake of insulin are the preferred choice for type II Diabetes, while, insulin and its analogs are the preferred therapeutic option in type I. Glimepiride is a frequently used anti-diabetic agent [3].

\section{GLIMEPIRIDE}

Glimepiride belongs to the third generation of sulfonylurea which is anti-diabetic agents. Glimepiride is preferred orally for patients with type 2 diabetes. It works by lowering the body's blood glucose level by promoting the release of insulin from beta cells of the pancreas [4]. It has a longer duration of action compared to other sulfonylureas and is metabolized by CYP2C9. Moreover, it also enhances the activity of peroxisome proliferator-activated receptorgamma (PPARgamma) [5].

It lowers blood glucose level by binding to the ATPsensitive potassium channel receptors in the pancreatic

*Corresponding Author: Safila Naveed, Faculty of Pharmacy, Jinnah University for Women, Karachi, Pakistan;

Email: safila117@gmail.com

Received: March 22, 2020; Revised: September 28, 2020; Accepted: October 01, 2020 DOI: https://doi.org/10.37184/lnjpc.2707-3521.2.6 cells thus, decreasing the conduction of potassium and causing depolarization of the membrane. Depolarization of the membrane causes the promotion of calcium ion influx through voltage-gated calcium channels. This in turn causes an increase of intracellular calcium ion concentration which ultimately induces the secretion of insulin [6] as illustrated in Fig. (1). The drug therapy is usually initiated at $1-2 \mathrm{mg}$.

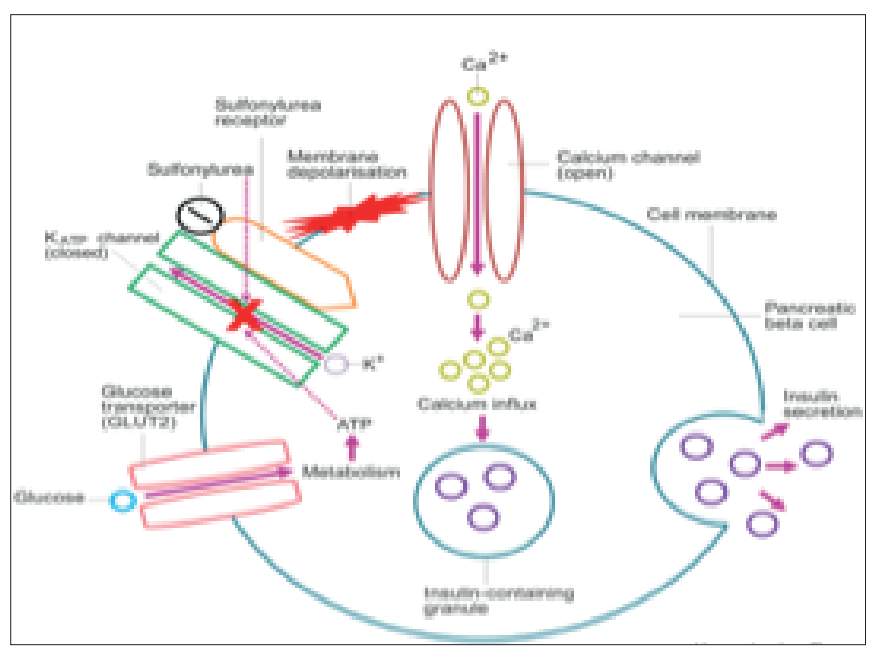

Fig. (1): Mechanism of action of Glimepiride.

The purpose of the present investigation was to compare different physicochemical parameters (weight variation, hardness, thickness, friability, disintegration time, and dissolution time) of 3 different brands of glimepiride commonly available in the market.

\section{MATERIALS AND METHODS}

A comparative physicochemical study was carried out by purchasing 3 different brands of glimepiride $(1 \mathrm{mg})$ 
tablet, namely Diabold, Amaryl, and Getryl available in the market (Table 1). The study had been conducted in January 2020 and all the experiments were performed in the Research Laboratory, Faculty of Pharmacy, Jinnah University for Women. The following parameters were tested to perform comparative analysis.

1. Weight Variation Test: 20 tablets of each brand were weighed using Electronic balance FX-400. They were observed for variation in their weight in comparison to the standard given by BP/USP which states that NMT 2 tablets out of 20 tablets should cross $\pm 10 \%$ deviation [7]. The test is important to ensure the uniformity of the dosage form. The upper control limit and lower control limit was also calculated by the following formula:

For upper control limit $=$ Mean $+3 x$ standard deviation For lower control limit $=$ Mean $-3 x$ standard deviation

2. Thickness Test: It is the degree of compaction. 10 tablets of each brand were analyzed for their thickness by using Vernier Calliper [8].

3. Hardness Test: Hardness refers to the crushing strength. We calculated the hardness of 10 tablets of each brand by using $\mathrm{MH}-1$ of Galvano Scientific hardness tester. It works by applying mechanical stress to compute the strength of the tablet. The tablet must be hard enough to bear the stress of NLT 4kg [9].

4. Friability Test: Tablet tends to chip ultimately effecting the elegance and appearance of the tablet. Besides, content uniformity as well as weight variation is also affected. 10 tablets of each brand were taken and analyzed on a friabilator at $25 \mathrm{rpm}$ or 100 rotations in 4 minutes.

According to the USP, the friability test should not deviate NMT 1\% [10].

5. Disintegration Test: This test is performed to check the time that a solid oral dosage form takes to disintegrate completely. Disintegration means the breakdown of the tablet which refers to the quality of dosage form. As specified by the USP, uncoated tablets should disintegrate within 15 minutes. If 1 or 2 tablets fail to meet the given criteria then the test should be repeated on the other 12 tablets, of which 16 out of 18 should disintegrate in a given time. The disintegration test was performed using disintegration apparatus DS-0702 using water as the disintegration medium. Each tablet was placed in each of the six tubes of the basket. The tablets were monitored until they completely disintegrated.

6. Dissolution Test: It is the process by which dosage form becomes accessible for absorption which means the rate of drug absorption can be determined by drug dissolution. It is a useful tool to check in-vivo bioavailability and hence bioequivalence.

According to the USP, each tablet should dissolve completely after 20 minutes at $50 \mathrm{rpm}$ at $37^{\circ} \mathrm{C}$. Tablet of each brand was placed in the vessel respectively. The solution was withdrawn at different time intervals and absorbance was measured at $273 \mathrm{~nm}$ using UV spectrophotometer. The resultant absorbance of each tablet brand was then compared with the standard to obtain the percentage release of each brand.

Table 1: Brand Profile.

\begin{tabular}{l|l|l|l}
\hline No. & Name of Product & Registration No. & Mfg. License No. \\
\hline 1 & DIAB & 030948 & 000457 \\
\hline 2 & AMAR & 019567 & 000007 \\
\hline 3 & GETR & 029437 & 000284 \\
\hline
\end{tabular}

\section{RESULTS AND DISCUSSION}

The present study was performed to compare the different commercially available brands of Glimepiride in Karachi, Pakistan. The brands were evaluated by the specified limits stated by the BP/USP.

Table 2 highlights the average weight, thickness, and hardness of the tablets of each brand. The average weight of each of the brands did not deviate from the pharmacopoeial specified limit i.e. $7.5 \%$. Similarly, thickness and hardness were found to also comply with the official pharmacopoeial limits.

The disintegration time of brands 1,2, and 3 was found to be $21 \mathrm{sec}, 10 \mathrm{sec}$, and $22 \mathrm{sec}$ respectively. Also, all the tablets were completely dissolved within 20 minutes with more than $80 \%$ of the drug being released. Table 3 highlights the result of the friability, disintegration, and dissolution test.

Table 2: Statistical weight, thickness, and hardness variation.

\begin{tabular}{|c|c|c|c|c|c|c|c|c|c|c|c|c|}
\hline Brands & $\begin{array}{c}\text { Average } \\
\text { Weight mg }\end{array}$ & STD & UCL & LCL & $\begin{array}{c}\text { Avg } \\
\text { Thickness mm }\end{array}$ & STD & UCL & LCL & $\begin{array}{c}\text { Avg } \\
\text { Hardness Kg }\end{array}$ & STD & UCL & LCL \\
\hline AMAR & 1.454 & 0.358 & 2.528 & -0.716 & 0.173 & 0.247 & 0.916 & -0.495 & 0.298 & 0.098 & 0.593 & -0.197 \\
\hline GETR & 0.973 & 0.369 & 2.081 & -0.739 & 1.03 & 0.357 & 2.102 & -0.714 & 0.345 & 0.128 & 0.731 & -0.257 \\
\hline
\end{tabular}


Table 3: Friability, disintegration, and dissolution of different brands of glibenclamide.

\begin{tabular}{c|c|c|c|c|c}
\hline Test & Accepted Limit & Result & Diabold & Amaryl & Getryl \\
\hline Friability (\%) & NMT 1\% & All passed & 0.08 & 10.10 & 10.16 \\
\hline Disintegration (Min) & NMT 15 min & All passed & 0.35 & 0.16 & 0.36 \\
\hline Dissolution (\%) & NLT 80\% & All passed & 85 & 90 & 93 \\
\hline
\end{tabular}

The statistical analysis of the results of the physicochemical tests revealed minor variations in each of the brands. It was found that Getryl showed the highest \% dissolution among all the 3 brands whereas Amaryl took the least time to disintegrate. According to the results of the friability test, Diabold shows the highest stability in the friabilator. By comparing the cost-effectiveness we found that Amaryl had the highest in price whereas Diabold was the most cost effective.

The results of our study were similar to the study conducted by Kassahan, where different brands of glibenclamide available in Ethiopia were evaluated for their in-vitro quality. All the in-vitro quality control parameters were found to be within the official pharmacopeial limits [11]. Another study also reported similar results where different brands of glibenclamide available in Saudi Arabia were compared [12].

\section{CONCLUSION}

Glimepiride is an effective anti-diabetic agent. The quality of the drug largely influences its therapeutic activity. The brands under study were found to comply with the official limits and hence, concluded the brands can be interchangeably used.

\section{LIMITATION OF THE STUDY}

The study had been performed only on 3 different brands of the Glimepiride. Increasing the number of brands will provide more options that can be interchangeably used with quality at the same time.

\section{CONFLICT OF INTEREST}

The authors declare no conflict of interest.

\section{ACKNOWLEDGEMENTS}

Declared none.

\section{REFERENCES}

1. Schernthaner G, Grimaldi A, Di Mario U, Drzewoski J, Kempler P, Kvapil $M$, et al. GUIDE study: double-blind comparison of once-daily gliclazide MR and glimepiride in type 2 diabetic patients. Eur J Clin Investig 2004; 34: 535-42.

2. Langtry HD, Balfour JA. Glimepiride. Drugs 1998; 55: 563-84.

3. Wu G, Wang L, Li J, Zhu W. Effects of glibenclamide, glimepiride, and gliclazide on ischemic preconditioning in rat heart. Chin Med Sci J 2007; 22: 162-8.

4. Yüzüak N, Özden $T$, Eren $S$, Özilhan S. Determination of glimepiride in human plasma by LC-MS-MS. Chromatographia 2007; 66: 165-8.

5. Dhindsa P, Davis KR, Donnelly R. Comparison of the micro-and macro-vascular effects of glimepiride and gliclazide in metformin-treated patients with Type 2 diabetes: a double-blind, crossover study. Br J Clin Pharmacol 2003; 55: 616-9.

6. Samala S, Tatipamula SR, Veeresham C. Determination of glimepiride in rat serum by RP-HPLC method. Am J Analyt Chem 2011; 2: 152.

7. Dilshad H, Naveed S, Rafiq A. Comparative study of four different brands of acetaminophen available in Karachi. World J Pharm Sci 2014; 2 : 586-90.

8. Naveed S, Dilshad H, Jaweed L. Comparative study of four different brands of ranitidine available in Karachi. Mod Chem Appl $2014 ; 2(125): 1-3$.

9. Naveed S, Dilshad H, Urooj S. A comparative study of loratadine physiochemical properties from different brands. Pak J Pharm Sci 2018; 31(6): 2569-73.

10. Naveed S, Waheed N. Comparative study of three different brands of doxycycline capsules available in Karachi. Open Access Lib J 2014; 1: 1-7.

11. Kassahun $H$, Asres $K$, Ashenef $A$. In vitro and in vivo quality evaluation of Glibenclamide tablets marketed in Addis Ababa, Ethiopia. J Pharma 2018; 2018: 7916368.

12. Alam MN, El-Gied AAA, Rahamathulla $M$, Fathey $M$, Shaker MAEF. A comparative in vitro dissolution of different brands of glibenclamide tablets available in Saudi Arabian market. Int J Adv Pharm Med Bioallied Sci 2017; 2017: 1-5. 